\title{
Correction to: Harden up: metal acquisition in the weaponized ovipositors of aculeate hymenoptera
}

\author{
Kate Baumann ${ }^{1}$. Edward P. Vicenzi ${ }^{2} \cdot$ Thomas Lam $^{2}$. Janet Douglas ${ }^{2} \cdot$ Kevin Arbuckle $^{3}$. Bronwen Cribb ${ }^{4,5}$. \\ Seán G. Brady ${ }^{6}$ Bryan G. Fry ${ }^{1}$ (D)
}

Published online: 16 June 2018

○) Springer-Verlag GmbH Germany, part of Springer Nature 2018

\section{Correction to: Zoomorphology \\ https://doi.org/10.1007/s00435-018-0403-1}

The author would like to correct the errors in the publication of the original article. The corrected details are given below for your reading.

In Elemental composition and distribution, eighth paragraph should read as "High concentrations of iron were found only in the aculeus of the giant vespid species Vespa mandarinia, while a high concentration of titanium was restricted to Miscocyttarus flavitarsus".

Updated version of Fig. 14 is provided below.

The original article can be found online at https://doi.org/10.1007/ s00435-018-0403-1.

Seán G. Brady

bradys@ si.edu

$\triangle$ Bryan G. Fry

bgfry@uq.edu.au

1 Venom Evolution Lab, School of Biological Sciences,

University of Queensland, St Lucia, QLD 4072, Australia

2 Museum Conservation Institute, Smithsonian Institution, Suitland, MD 20746, USA

3 Department of Biosciences, College of Science, Swansea University, Swansea SA2 8PP, UK

4 Centre for Microscopy and Microanalysis, The University of Queensland, St Lucia, QLD 4072, Australia

5 School of Biological Sciences, University of Queensland, St Lucia, QLD 4072, Australia

6 Department of Entomology, National Museum of Natural History, Smithsonian Institution, Washington, DC 20560, USA 
Fig. 14 Ancestral state reconstructions over branches for titanium where warmer colours represent a higher concentration of titanium in the aculeus

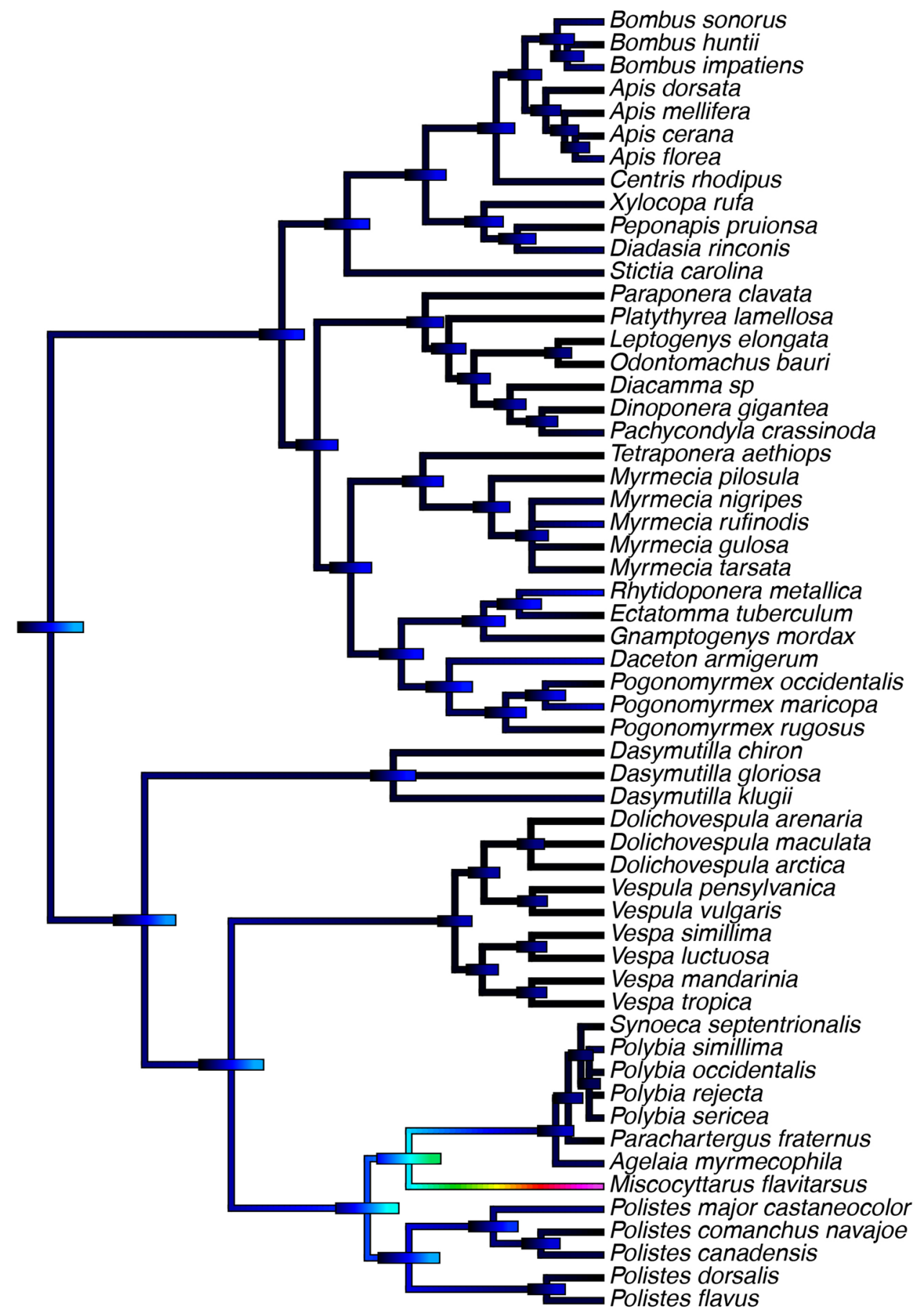

0 trait value 1

length $=0.5$ 